\title{
LA IMAGEN DE LA MUJER ESPAÑOLA DURANTE EL SEXENIO: ENTRE EL CAMBIO SOCIAL Y EL RECONOCIMIENTO JURÍDICO
}

\author{
CARMEN BOLAÑOS MEJÍAS \\ Universidad Nacional de Educación a Distancia
}

\section{INTRODUCCIÓN}

Para aproximarnos a la realidad de la mujer española de finales del siglo XIX hemos partido de una perspectiva que consideramos esencial: la estructura familiar como sistema de valores, contemplando la familia como una disposición elemental dentro de la cual tiene lugar cualquier adaptación a unas relaciones sociales en evolución. La familia es un factor clave para entender no sólo la posición de subordinación de la mujer, sino también la visión negativa que se tenía de la misma. Las casadas, por el hecho de serlo, estaban sometidas al marido, al revés de lo que ocurría con los hombres. La condición de esposa suponía un cambio sustancial en la personalidad jurídica y una clara delimitación de atribuciones que respondían a su ubicación en la organización familiar dominante, condicionada por normas jurídicas y también por ideas y categorías culturales que guiaban y legitimaban la acción.

Pero, en conjunto, este estudio es el reflejo de una preocupación por alcanzar una mejor y más profunda comprensión de la realidad, desde planteamientos que otorgaban a la mujer y a lo femenino un protagonismo más acorde con su verdadero significado humano y social. Por ello queremos destacar la influencia cultural sobre la familia, el modelo doméstico que en el siglo XIX proporcionaba los valores de jerarquía, obediencia y autoridad, orientando tanto el pensamiento como el comportamiento de hombres y mujeres y que nos permite contrastar la realidad de la mujer, ajena por completo al marco normativo vigente. No obstante, a pesar de esta exclusión política, la mujer consiguió convertirse en protagonista de una cuestión delicada.

A partir de la revolución de 1868, la clase política dirigente comprendió la conveniencia de interesarse por las demandas reivindicadas por el pueblo y, puesto que las reformas estructurales eran impensables, idearon otras fórmulas, entre ellas la de especular en torno a la mejora de las condiciones de vida de las 
clases sociales más desfavorecidas. La burguesía tuvo conciencia de la progresiva concienciación de los núcleos obreros, radicalizados y organizados sobre todo a partir de la aparición en España de la I Internacional en 1870. Entendió que la represión sistemática y el silenciamiento de las reivindicaciones proletarias no eran freno suficiente ante la presión que ejercían los pobres por mejorar sus condiciones de vida.

De acuerdo con lo anteriormente expuesto, podemos acercarnos a las causas que determinaron la inclusión de la mujer en cualquier plan con proyección política de finales del XIX. Para los políticos se trató simplemente de poner en marcha un mecanismo eficaz que permitiera a sus promotores controlar y frenar la progresiva concienciación de las mujeres, radicalizadas sobre todo a partir de los acontecimientos revolucionarios de 1868. En realidad la mayoría de las alternativas propuestas no llegaron a materializarse y del contenido de las publicaciones, los debates y los informes emitidos en el desarrollo de dichos trabajos se puede deducir que el esfuerzo oficial tan sólo pretendió armonizar sus relaciones con las mujeres, estableciendo unas vías de diálogo y acercamiento ajenas al foro político. El Sexenio dio paso a una realidad social que reclamaba algún tipo de respuesta de los líderes políticos, en su mayoría intelectuales liberales que reconocían la necesidad de procurar soluciones burguesas para los problemas del pueblo ${ }^{1}$. Preocupación que tuvo que asumir el gobierno mostrándose partidario de promover, analizar y debatir los estudios que proyectaban reformas de asuntos que, en realidad, no se querían reformar.

Estas medidas marcan nuestro punto de partida, pero el objetivo de este trabajo no se centra en el estudio de las mismas, sino en describir el ambiente en el que los distintos grupos dirigentes tuvieron que enfrentarse a una problemática nueva, distinta en alcance e intensidad. La cuestión social empezaba a disputar primacía a los intereses estrictamente políticos y a pesar de que el tratamiento que aquellos recibieron fue escaso, no deja de ser significativo que las pocas reformas que se propusieron fueron consecuencia inmediata de la reacción temerosa de las clases altas y medias ante el miedo a la radicalización de las demandas populares y a las posibles alteraciones del orden en una sociedad que rechazaba política y jurídicamente los movimientos populares organizados.

\section{MUJER Y SOCIEDAD}

El hecho de que la mujer estuviera subordinada al hombre, junto a la pervivencia de estructuras del Antiguo Régimen y el control social ejercido por la Iglesia Católica hicieron que su concienciación política fuese lenta, ya que la mujer estaba resignada a ver la desigualdad sufrida como su realidad presente

1. Asociación de Enseñanza Universal, artículo $1^{\circ}$ : "Cuando el espíritu de la civilización, tanto tiempo adormecido en España, se despierta potente y vigoroso en nuestra sociedad, extendiendo sus benéficas luces en todas las clases y por todas las instituciones, no puede la mujer española, ardiente y entusiasta por naturaleza, permanecer indiferente al progresivo desarrollo de la ilustración...» (Memoria del Ateneo de Señoras, Madrid, Rojas, 1869). 
y su futuro inevitable. Esta idea fue asumida con tanta naturalidad por la mujer que se responsabilizó de transmitirla a sus hijas, educándolas conforme a un estereotipo: toda mujer debía estar subordinada a la acción de los hombres más próximos a ellas, asumiendo su desigualdad jurídica y civil. El panorama no podía ser más desalentador, el destino de las mujeres quedaba al arbitrio de los hombres, siendo finalmente ellos quienes se encargarán de plantear la polémica en el marco de la lucha por las mejoras sociales, marco en el que la mujer centró la reivindicación de sus intereses, dentro, pues, de unos asuntos ajenos a los principios políticos y que acabarían condicionando las concretas conquistas conseguidas por la mujer en el conjunto social. En general su lenta concienciación política fue acompañada, en íntima relación causa-efecto, de una transformación ideológica.

Pero, en contra de lo que pensaban los políticos liberales, las innovaciones de cualquier tipo fueron una excepción $y$, aunque aquellos defendían el derecho de todos los ciudadanos, no supieron sustraerse, a la hora de tratar los asuntos que afectaban a la mujer, a su propia realidad y a los prejuicios sociales de la época. Convencidos, como estaban, de que el modelo adjudicado a la mujer era el más conveniente, quisieron asegurarlo a través del tipo de educación que ésta recibiría, lo que a la par les valía también para controlar la propagación de sus ideas.

Para conseguirlo, sublimaron las relaciones que se establecían entre madres e hijas, en un contexto social donde la mayoría de las mujeres eran analfabetas y la expresión oral era su único medio de comunicación y, por lo tanto, elemento fundamental de adoctrinamiento y aprendizaje. Se estimó oportuno mantener la continuidad de ciertos hábitos familiares y se adoptaron las creencias populares como elementos conformadores de la mentalidad vigente. Reconocidas estas premisas por las clases dirigentes, le dedicaron una atención preferente, por lo que no dudaron en incluir en sus discursos la necesidad de acometer la tarea de instruir a las mujeres, con el objeto de capitalizar los beneficios para la tendencia ideológica que representaban. Y, aunque pretendieron canalizar los problemas de la mayoría de las mujeres de la época, no lo consiguieron, sin duda porque su objetivo se fijó en relegar a la mujer a unas determinadas funciones en el seno familiar, identificando un grupo concreto de mujeres, las de la casi inexistente clase media, con el conjunto de la población femenina. Desde el punto de vista masculino, la causa de la discriminación femenina era doble: de un lado, esa marginación social tenía unas causas que provenían de su sexo, una limitación natural que les impedía ser objetivamente racionales y justificaba la incapacidad de la mujer para participar en cualquier tipo de conversación; de otro, la carencia de instrucción.

Tanto los políticos como los intelectuales validaban esta hipótesis denunciando la ignorancia general de las mujeres y destacando la necesidad de remediarla: 
«... comienza á respetar el varón la peculiar excelencia y dignidad de la mujer, trabajando por mejorar su cultura, y educando todas sus potencias y facultades en relación proporcionada con su carácter y destino». ${ }^{2}$

Dada la limitada capacidad de la mujer para adquirir conocimientos de nada serviría que la formación se redujese a instruir o alfabetizar, había que incluir otros objetivos más acordes con las tendencias femeninas. La influencia directa de la mujer sobre los hábitos de los niños era fundamental $\mathrm{y}$, precisamente porque se detecta un acelerado proceso reivindicativo en las clases populares, la mujer se convirtió en una pieza fundamental.

El objetivo era atraer a los hombres a través de las mujeres y de ahí el interés que suscitaban entre los dirigentes políticos las reivindicaciones femeninas. Y mientras los legisladores ambicionaban regular la formación femenina, la Iglesia recomendaba a sus fieles la instalación de casas de enseñanza, valorándose "la educación cristiana que ellas darán a tus hijas, que de tus hijas se comunicará a las familias, y que de las familias se propagará a la población entera», viéndose en este modelo educativo la fórmula más eficaz de devolver al pueblo "la moralidad y la dicha que le arrebataron las malas doctrinas» ${ }^{3}$. Frente a los bienintencionados propósitos, se situaban la mayoría de las mujeres, también afectadas por la mentalidad de la época, pero que tan sólo reclamaban soluciones para sus problemas inmediatos, siendo su principal preocupación luchar por mejorar sus condiciones de vida, por lo que, antes que otras cuestiones, se veían obligadas a pedir casa, pan, salud y trabajo.

2. Juan RADA y DELGADO era catedrático de la Escuela de Diplomática y habló sobre la «La educación de la mujer por la historia de otras mujeres», Ciclo de Conferencias Dominicales sobre la Educación de la Mujer de la Universidad de Madrid, Madrid, Rivadeneyra, 1869.

3. RANAS, J.: El cura en el púlpito, obra original predicable compuesta en obsequio del venerable clero parroquial de España, por el P. Lector..., Gerona, 1868, pp. 194-195. Alude a la necesidad de prestar una atención preferente al púlpito, al confesionario y a la literatura religiosa, como elementos conformadores de una mentalidad. Sin duda, la necesidad de acomodarse al vivir cotidiano debió verse muy afectada por las tensiones originadas por motivos religiosos. Mención especial merecen las publicaciones dedicadas a instruir sobre el noviazgo o el matrimonio, en los que junto con consejos jurídicos y religiosos aparecen otros dirigidos a «hacerse querer del marido». Para ello bastaba con no contradecirle ni sermonearle, abstenerse de entrometerse en cuestiones económica y de aparentar talento. Así se desprende de la Guía para la dirección de las Hermanas de Enseñanza de la Purísima concepción, dadas por el Excmo. Sr. D. José Domingo Costa y Borras, obispo de Barcelona, Barcelona, 1851 o la Instrucción de un padre a su hija sobre las materias más importantes de la religión, costumbres y modo de portarse... de DupuY, Barcelona, 1831. Estos escritos han sido sistematizados por Simón PALmer, M.C.: «La mujer en el siglo XIX: notas bibliográficas», Cuadernos Bibliográficos, 31 y 32 (1974 y 1975), pp. 141-198 y 109150 respectivamente. 


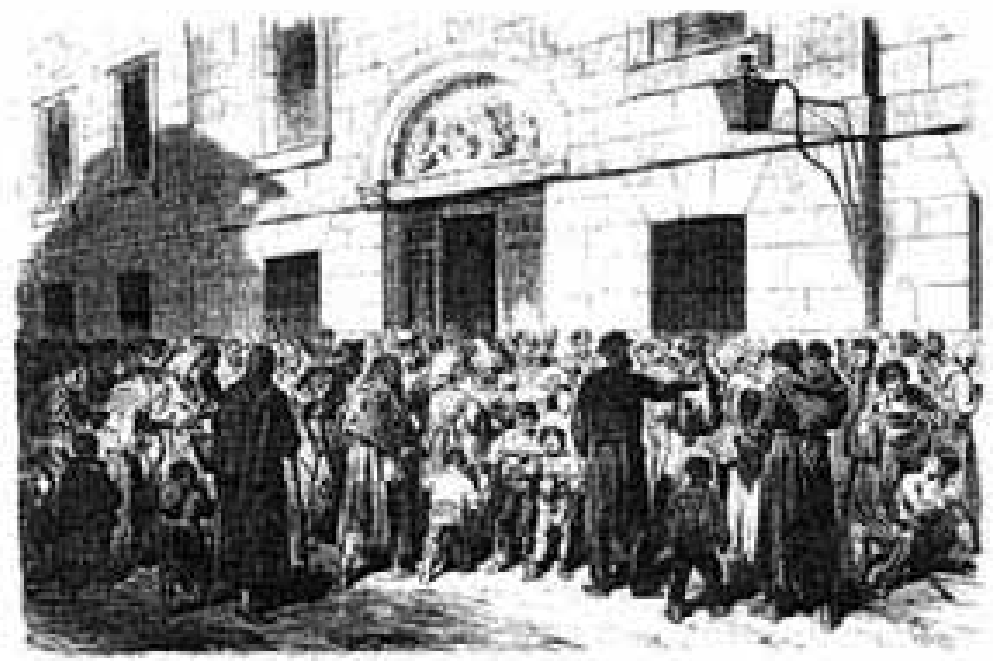

«Distribución de la comida que diariamente costea S.M. la Reina para los pobres de Madrid» (La Ilustración Española y Americana, n² 25, 15 de diciembre de 1871)

\section{EL RECONOCIMIENTO DE LA EDUCACIÓN FEMENINA, UNA EXIGENCIA DEL PROGRESO SOCIAL}

El que los liberales de 1869 participaran en el debate del estado de la enseñanza femenina no encerraba una actitud de denuncia, era el modo de contar con un argumento favorable antes de abordar la defensa del derecho que asistía a cualquier hombre a educarse. Por esta razón quienes más se comprometieron con esta empresa fueron los componentes del círculo krausista de Sanz del Río, intelectuales sensibilizados con la extensión de la enseñanza a sectores cada vez más amplios. Aunque tan sólo se trataba de la lógica consecuencia de la inquietud sentida por una clase media minoritaria que se esforzaba por la instrucción de niños y pobres como una señal de progreso, fueron consecuentes con sus demandas y se vieron abocados a tener que incluir también a la mujer.

Sin embargo cuando se hablaba del futuro de la mujer, era para alentarla a esperar «... con paciencia... que llegue quien ha de graduarla con el título de esposa ${ }^{4}$. Estas declaraciones no deben extrañarnos, porque nunca se pensó en dotar a las mujeres de formación, tan sólo se quería conformar sus costumbres y sus ideas para prepararlas socialmente; es decir para lo que los hombres esperaban de ella. Lo que explica que la formación femenina fuese sobre todo práctica y desde luego específica, es decir diferente. Lo que suponía en definitiva fijar en la mente de las españolas la idea del matrimonio como fin ideal; la casa, su lugar natural; la familia, su primordial preocupación.

4. Francos Rodriguez, José: La mujer y la política españolas, Madrid, Pueyo, 1920, p. 231. 
Con respecto a estos objetivos no existían diferencias entre los que se oponían a la implantación de los principios liberales y los que defendían el régimen democrático al que se aspiraba. En este asunto existía un general consenso: la mujer teóricamente tenía igual derecho e idéntico deber que el hombre a instruirse para que le fuera posible realizar la misión que como persona se le asignaba y para que lo hiciese con las mayores garantías de éxito. Así enunciada, la causa no podía resultar más justa, en clara correspondencia con el ejercicio del principio de igualdad al que se aspiraba.

Pero el tipo de enseñanza planteado y los fines vitales asignados a la mujer le fueron reconocidos en relación siempre con el lugar que ésta tenía asignado dentro de la familia. Todos coincidían en señalarla como el conducto por el cual la mujer colaboraba al devenir social; su misión era hacerse madre; su puesto estaba en el seno familiar y por ello se dio prioridad a las labores familiares, y se descartaron las que desarrollaba fuera de dicho ámbito.

Ahora bien, se pretendió iniciar un proyecto de futuro para corregir lo importante, el alto índice de analfabetismo de los españoles. Este era el primer paso para eliminar el subdesarrollo del país e ir preparándolo socialmente para el ansiado progreso político y social. La inclusión de la mujer en esta campaña no puede entenderse como una actitud altruista, sino como una obligación para activar su opinión a fin de ejecutar los planes elaborados. Así lo entendieron las figuras intelectuales y políticas que abogaron a favor de una educación femenina diferente, como Joaquín $M^{a}$ Sanromán, Juan de Dios de la Rada y Delgado, Francisco de Paula Canalejas, Fernando Corradi, Ramón María de Labra, Santiago Casas, Segismundo Moret, José Echegaray, Gabriel Rodríguez, Florencio Alvarez Ossorio, José Moreno Nieto, Tomás Tapia, Antonio María García Blanco y Francisco Pi y Margall, participantes en las Conferencias Dominicales para la Educación de la Mujer, inauguradas el 29 de febrero de 1869 en el Salón de Grados de la Universidad Complutense.

Las Conferencias pretendían servir como instrumento para conseguir un amplio consenso social a favor de la instrucción femenina a la par que contribuirían a «... fijar los puntos más importantes sobre los que debe versar la instrucción de la mujer, esclareciendo (su) concepto... en los diversos órdenes y fines de la vida», según afirmaba su promotor Fernando de Castro en la conferencia inaugural ${ }^{5}$. Ahora bien, tales argumentos apenas consiguieron encubrir las auténticas razones en que se basaban. Los discursos iban dirigidos a la mujer en un intento de estimular su conciencia solidaria, de hacerle evidente la importancia de su contribución en el mantenimiento del orden social. Se trataba de excitar la intervención de la mujer como interlocutora con la clase proletaria, para que fomentara entre los hombres que con ella se relacionaban el deber de mejorar su educación social.

Ahora bien, la campaña, si no fue por fidelidad a unos ideales, tuvo que asumir unas consideraciones de tipo práctico, de forma que se constituyó en

5. Jiménez Landi, A.: La Institución Libre de Enseñanza, Madrid, Taurus, 1972, pp. 88-101 y 395-402. 
el primer paso para acercarse a la mujer, familiarizándola con unos postulados que se pretendía que asumiera. Pero aún procuraba otro objetivo: era también un método de sensibilizar a la mujer como fuerza social, haciéndole evidente la preocupación que entre el resto de su clase o en otros estamentos suscitaban sus problemas y permitiéndole, como prueba fehaciente de compromiso, que fuera ella misma quien participara en la exposición de las mejoras a las que aspiraba.

Las declaraciones de los implicados nos demuestran que en realidad se trataba de simples declaraciones de intenciones que ante circunstancias concretas quedaron sin efecto, porque

«faltan moralidad en las costumbres, armonía en la existencia, recursos para la educacion y base para el progreso; ... explicar qué órden de estudios y qué género de trabajos cuadran mejor á la naturaleza delicada y al espíritu sintético de este bello y adorable sér» ${ }^{6}$.

Así pensaban los liberales, quienes con atisbos de recomendación incluían algunas declaraciones sorprendentes como la de

«Por poco que vuestra atención se haya fijado en la marcha de los intereses sociales y el progreso de las ideas políticas en estos últimos años, es seguro que habréis advertido más de una vez en libros y en periódicos una frase, apénas enunciada, corregida y abrumada con "peros", invectivas y críticas de toda especie. Esta frase es LA EMANCIPACION DE LA MUJER. La idea, sin duda alguna, es grave, y harto lo habréis observado al reparar que las críticas, de ordinario, se refieren á dos puntos que se señalan como consecuencias imprescindibles de aquel principio. Estas consecuencias son: "la prostitución de la mujer en la vida política, y la disolución completa de la familia en la vida civil" ${ }^{7}$.

Quien así opinaba, Rafael M. Labra, fue diputado demócrata por Puerto Rico y reclamaba la abolición de la esclavitud. Pero el principio de igualdad que defendía para todos los hombres no se extendía a las mujeres, a las que recomendaba prudencia frente al progreso. No se trataba de una opinión aislada, incluso el republicano Pi y Margall sostenía que «si la mujer es pobre y tiene que dedicarse al trabajo, bajando al fondo del taller, de la fábrica,... esa pobre mujer, que baja al fondo del taller, cree, por otra parte, que así contribuirá al sostén de su familia, y ni aún esto logra» ${ }^{8}$, por lo que no dudaba en recomendarle que empeñara sus esfuerzos en el hogar.

La forma en que todos los conferenciantes plantearon el tema de la enseñanza de la mujer supuso un éxito para la iniciativa de Castro y, sin duda, amplió el ámbito de resonancia de sus ideas junto a la respuesta gubernamental, que no se hizo esperar, poniéndose la idea en marcha con la creación de dos ins-

6. Rafael M. LABRA, como abogado, centró su intervención en los derechos de la mujer con el título: «La mujer y la legislación Castellana», en Ciclo de Conferencias Dominicales..., op. cit., p. 5.

7. Ibíd., p. 10.

8. «En el hogar doméstico tiene la mujer su teatro, su asiento, su trono». Vid. PI y MarGaLl, Francisco: "La misión de la mujer en la sociedad" en Ciclo de Conferencias Dominicales..., op. cit., p. 5. 


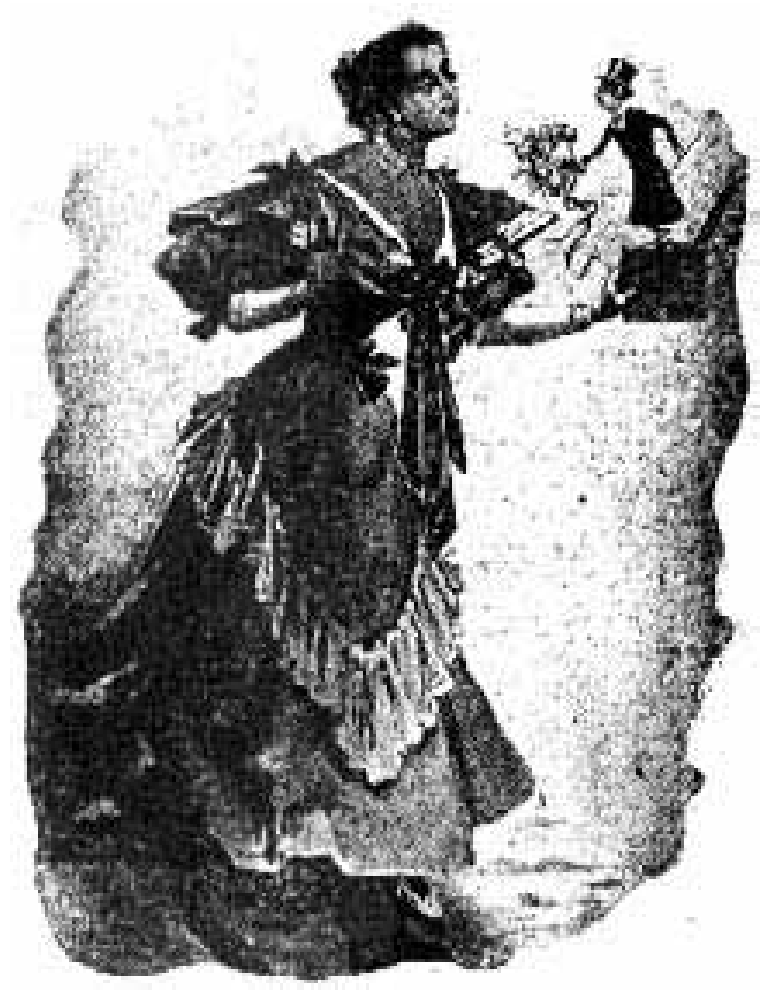

«Lo que ellas esperan del 96» (Nuevo Mundo, n² 2, 9 de enero de 1896)

tituciones específicas para la formación femenina: La Escuela de Institutrices, inaugurada el 1 de diciembre de 1869 y la Asociación para la Enseñanza de la Mujer, surgida en 1870. De este modo se pretendía dar satisfacción a un problema, a la vez que se acometía la tarea de concienciar a la mujer de que no debía descuidar su tradicional papel de esposa y madre.

\section{LA MUJER, BALUARTE DE LA SOCIEDAD}

Para alcanzar los objetivos de los planes elaborados, se puso en práctica una campaña que divulgase las nuevas ideas y captase con mayor facilidad a las mujeres. Los líderes políticos buscaron apoyo en las «señoras», apelando a los «naturales» sentimientos caritativos, y a las tradicionales actividades benéficas que siempre habían desarrollado quienes pertenecían a las clases acomodadas?.

9. El 31 de octubre de 1868 el gobierno provisional encargó a Concepción Arenal que restableciera la inspección general de las Casas de corrección de mujeres. Esta actividad se circunscribía a la colaboración que solicitaba el Gobierno a la mujer desde la perspectiva de atender la caridad y la beneficencia. Así en la exposición de motivos del Decreto de 3 de noviembre del mismo año el 
La campaña significó, en cambio, un primer paso para acercarse a la mujer, para incorporarla a la sociedad como individuo. Se trataba de guiarla por un camino rutinario, por sendas que solicitaban clemencia, cuando era justicia lo que se tenía que exigir. Por más que esta vía fuese considerada por algunas mujeres más que suficiente para convencer a las que dudaban, atraerse a las escépticas y conseguir cambios ajenos a cualquier principio político.

Estas colaboradoras participaban de la dinámica gubernamental, aun escribiendo manuales de conducta y ficciones domésticas, aceptaban el peso de la tradición. Descendían de la clase alta y media, transigían con los valores femeninos del pasado en la misma medida en que tomaban conciencia de la transformación social del país, reaccionando y anticipando ciertos ideales. No se empeñaban en obtener el reconocimiento masculino, sino que adoptaron conductas de flexibilidad política e incluso de oportunismo para aprovecharse de sus contactos gubernamentales. De modo que, a través de su participación en las instituciones educativas o a través de sus publicaciones, fueron superponiendo las inquietudes del liberalismo a los contenidos de las primeras tesis que solicitaban la participación creciente de la mujer en todos los ámbitos.

El ideal femenino permanecía dentro del entorno doméstico y reducía sus funciones a la maternidad o, a lo sumo, a cierto influjo moral. Sin embargo, una tipología de estas características permitía a las mujeres la reivindicación de ciertos espacios de independencia económica. Se trataba de considerar situaciones extremas, como podía ser el caso de las solteras o las viudas, dentro de unas circunstancias que no se contemplaban como la meta a la que debía aspirar cualquier mujer, pero que, en una estructura económica como la que se imponía, hasta cierto punto impredecible, exigía que se contemplara como una alternativa para situaciones de desamparo ${ }^{10}$. Este resquicio lo aprovecharían las mujeres para insistir en la necesidad de estar preparadas para una posible situación de descenso social, coyuntura ante la que podrían encontrarse dentro de un contexto de incertidumbre capitalista ${ }^{11}$.

Gobierno consideraba que, «nadie puede disputar á la mujer la palma de los afectos caritativos organizada espléndidamente para todo lo que exige bondad, ternura, simpatía y abnegación", por lo que se legalizaba la existencia de las antiguas asociaciones de señoras, previa la presentación y aprobación de los Reglamentos que no fueron autorizados por los gobierno anteriores. En el artículo $2^{\circ}$ se instaba a los Gobernadores civiles a que invitasen a las señoras a colaborar con dichas asociaciones. Recogido de Disposiciones adoptadas y publicadas por el Ministerio de la Gobernación desde el 9 de octubre de 1868 hasta la apertura de las Cortes Constituyentes, Madrid, Imprenta de Rojas, 1869, pp. 69 y 71 respectivamente.

10. «Los padres no pueden asegurar á sus hijos una fortuna por muchas riquezas que posean, porque los bienes de la tierra son perecederos...» en SÁEZ de MeLGar, Faustina: Manual de la joven adolescente o un libro para mis hijas, Barcelona, Jepus, 1882, $2^{\text {a }}$ ed., p. 66.

11. Sobre la incorporación de la mujer al trabajo, Rosa $M^{a}$ CAPEL dice: "De igual modo que ocurriese en otros países, será la evolución económica interna la que familiarice a los españoles con la idea de la actividad asalariada femenina, aunque no se supere esa postura intermedia que la acepta ante el imperativo de las circunstancias y que, por tanto, no deja de concebirlo como complementario, eventual, mal menor antes de morir de indigencia o perder la honra». Vid. "Mujer y trabajo en la España de Alfonso XIII", en Ma Ángeles DuRÁn y otros: Mujer y Sociedad en España 1700-1975, Madrid, Ministerio de Cultura, 1982, p. 214. 
El impacto de esta cultura femenina se detectó a partir de 1870, desarrollándose a través de la lectura popular. Dinámica que debemos matizar, pues el escaso número de potenciales mujeres lectoras hizo que cualquier publicación femenina tuviera como público preferente al lector burgués, masculino o femenino. De nuevo fueron aceptados estos inconvenientes por las pocas mujeres que se atrevían a dar a conocer sus publicaciones, que solían tratar de temas dedicados al ocio doméstico o de interés femenino. Estas mujeres carecían de propósitos beligerantes y su actitud les permitió legitimar un periodismo burgués y mundano, pero realizado por unas escritoras que, al servirse del apoyo masculino de un editor profesional, recibían el elogio del resto de la sociedad.

Este fue el caso de Faustina Sáez de Melgar, quien en el Sexenio apoyó al gobierno del interregno (1868-1870) y presidió el Ateneo Artístico y Literario de Señoras, institución creada en 1869 bajo el auspicio de los krausistas. En 1871 dirigió la revista La Mujer al servicio de la Monarquía de Amadeo I (1870-1873). Pero, fue precisamente en el Ateneo de Señoras donde reformuló su perspectiva pedagógica sobre la instrucción femenina: preparar a la mujer burguesa española para el desempeño de un trabajo intelectual que evite su proletarización en caso de desamparo ${ }^{12}$. Sáez de Melgar se manifestaba convencida y explícita en sus posiciones:

"la mujer no debe salir de las atribuciones esenciales del hogar doméstico. Idea que acato, que apruebo y que sustentaré siempre; ése es su terreno propio, el puesto de la mujer está junto a la cuna de sus hijos; allí he escrito todas mis novelas, y no por eso he dejado de cuidarlos y de lactarlos a mi propio seno» ${ }^{13}$.

Estas declaraciones reflejan una actitud tradicional, pero el hecho no debe sorprendernos, toda vez que en el terreno de la formación femenina se estaban dando los primeros pasos. Su postura era congruente con las circunstancias concretas del país y el tipo de enseñanza que proponía lo era con sus ideales. A tales fines, tal educación.

El 1 de diciembre de 1869, se inauguró la Escuela de Institutrices, en los locales de la Escuela Normal madrileña y bajo la dirección de doña Ramona Aparicio $^{14}$. Para ingresar en la Escuela bastaba con saber leer y escribir, tener nociones de gramática castellana y algunas de aritmética. Acreditados tales conocimientos ante un tribunal, las alumnas eran instruidas durante tres cursos. Pero la efectividad de estas iniciativas fue muy limitada. La enseñanza establecida no comportaba un cambio en los conceptos y contenidos, a lo sumo tratará de extender su ámbito.

Un año después, los discípulos de Sanz del Río establecieron la Asociación para la Enseñanza de la Mujer, la primera institución destinada a convertirse en

12. Sáez de Melgar, Faustina: Memoria del Ateneo de Señoras, Madrid, Imprenta de Rojas, 1869, p. 19.

13. Ibíd., p. 17.

14. Según la propia directora la finalidad de la Escuela era «... dar a las jóvenes los elementos más indispensables de la cultura intelectual, moral y social propia de la mujer, y preparar a las que han de dedicarse a la enseñanza y a la educación». Artículo $1^{\circ}$ del Reglamento de la Escuela de Institutrices. Cfra. Asociación para la enseñanza de la mujer. Bases de la misma y Reglamentos de sus Escuelas, Madrid, Tello, 1979, p. 10. 
centro coordinador de actividades e impulsor de cuantas iniciativas se consideren necesarias para "fomentar la educación e instrucción de la mujer en todas las esferas y condiciones de la vida social» ${ }^{15}$.

El primero de los objetivos enunciados estaba prácticamente cubierto, el segundo sin embargo era un terreno aún virgen. Los ideales renovadores de cuantos compartían inquietudes pedagógicas encontraron un eco minoritario entre quienes, de un modo u otro, eran responsables de la educación femenina. Casi el mismo interés mostraron quienes serían sus directas beneficiarias.

\section{LA MUJER Y SU ENTORNO: DE LA CARIDAD AL RECHAZO}

De la anterior somera instrucción quedaba privada la mayor parte de la población femenina. Precisamente el alto índice de analfabetismo excluía a una parte importante de las destinatarias, que eran las más pobres. No asistían a la escuela, bien por falta de medios económicos, por falta de locales, o simplemente por costumbre. Lo habitual era que, dado el trabajo que esperaban realizar estas mujeres, desde el momento en que tenían que mantenerse, consideraran la educación ofrecida como superflua o innecesaria: "Esta mujer, si sabía de lectura, no conocía más libros que el de Misa, el Año Cristiano y el Catecismo, que enseñaba a sus hijos... ${ }^{16}$. Estaba encaminada a dedicarse preferentemente al servicio doméstico, teniendo en cuenta que tan sólo sabía realizar tareas consideradas tradicionalmente como las elementales y obligadas a su condición de mujer. Estas tareas eran asumidas con tanta naturalidad que impedía, en general, que se reconociese que la mujer que fregaba, hacía la compra, cocinaba y limpiaba, realizaba un trabajo y en consecuencia fuese una trabajadora. Lo cual, unido a otros factores, como el de la escasa cualificación, su procedencia mayoritariamente rural y las irregularidades en los mecanismos de contratación, provocaban que el mercado de sirvientas se caracterizara por su inestabilidad.

A pesar de todo, el sirviente doméstico en la sociedad urbana de finales de siglo desempeñaba como mínimo otro papel distintivo. Su presencia podía definir a las clases más privilegiadas de la sociedad, como signo de ostentación. En este caso, se trataba de sirvientas especializadas con cualificación profesional que debían satisfacer mayores necesidades de servicios que en el caso de una familia de clase media o alta. Cierto que su trabajo tenía mucho de exhibicionismo, como indican sus cuidados uniformes y la frecuente exposición pública que se hacía de ellas en paseos y lugares públicos ${ }^{17}$.

15. Ruiz de Quevedo, Manuel: «La Asociación para la Enseñanza de la mujer», Boletín de la Institución Libre de Enseñanza, 143 (1883), pp. 17-18.

16. PARdo BAZÁn, Emilia: «La mujer española», La España Moderna, 17 (1890), pp. 101-113.

17. TeSTe, Luis, nos describe así El Prado: «A las cuatro de la tarde la calle de Alcalá, que es la gran arteria del Prado, está rebosante de coches, caballos, gente del pueblo, de curiosos..., señoras y señoritas, oficiales, soldados, niñeras, nodrizas... El Prado es un salón, o mejor dicho, un teatro... creo que la vida aquí es más bien exterior y que en el hogar se hacen algunos sacrificios para que la cola del vestido sea más amplia y el encaje más costoso", en su obra Viaje por España, Valencia, Castalia, 1959, p. 64. 


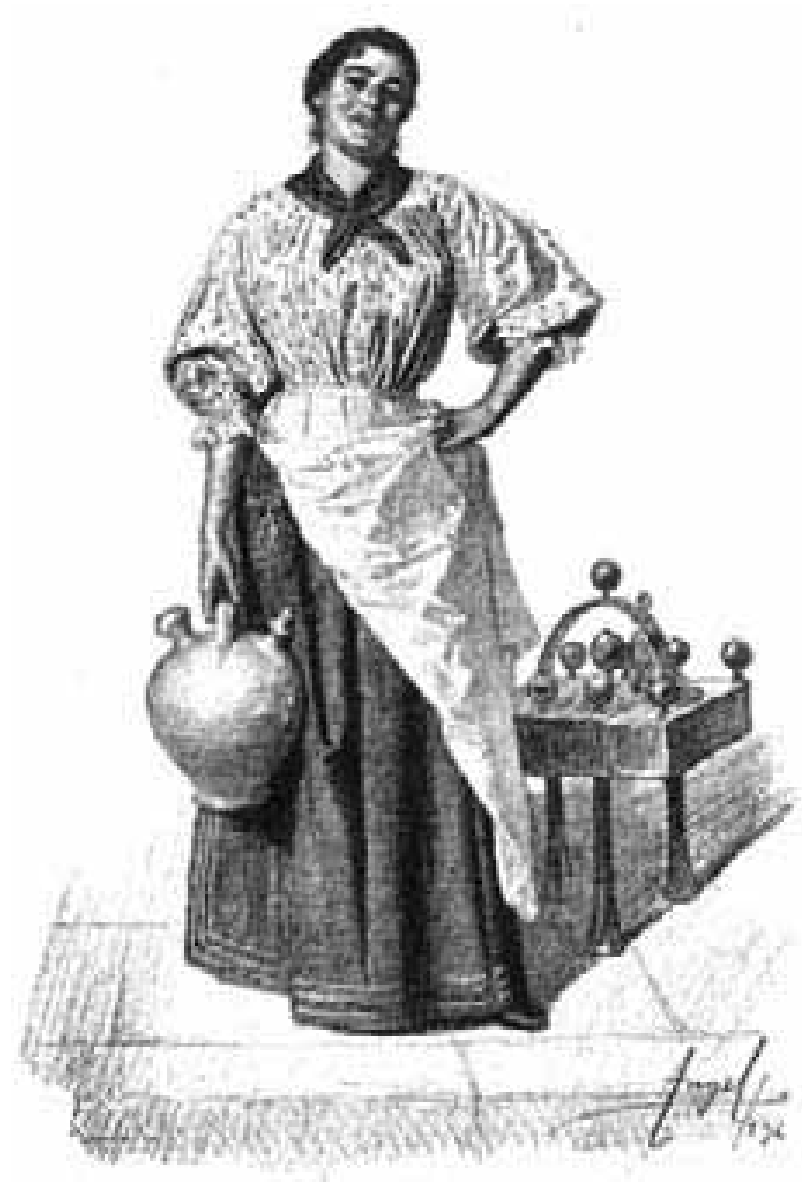

«Agua fresca!» (Nuevo Mundo, n 36, 13 de agosto de 1896)

En esta élite de los sirvientes abundarán los hombres. Este uso preferente de servicio masculino se explica porque, al ser sujetos más valorados socialmente, exhiben con mayor rotundidad la categoría de su señor. Si en las comidas de medio tono pueden servir la mesa las criadas, en las grandes comidas de ceremonial era de ritual que sirviesen criados vestidos de frac, corbata y guantes blancos ${ }^{18}$.

Al margen se encontraban una serie bastante amplia de variadas ocupaciones que se abastecían principalmente de mujeres y muchachos jóvenes. Procedían, por lo general, de las inclusas, de donde salían a trabajar como aprendices, recaderos y criados en casas sin grandes posibilidades económicas. Por lo regular se iniciaban muy jóvenes y durante muchos años sólo ganaban un

18. El salón de la Moda, 7 de abril de 1890. 
salario mínimo. Y es que no sólo las familias ricas tenían sirvientes en Madrid: funcionarios, tenderos, patronas de pensiones, trabajadores autónomos tenían también sus criadas. En su caso, el servicio no era únicamente un elemento de ostentación, siendo en estas circunstancias donde mejor se refleja el papel que desempeñaban las criadas: "Se necesita una criada, de treinta a cuarenta años, que sepa con perfección coser, lavar, planchar, comprar, guisar y fregar con aseo, siendo muy limpia hasta consigo misma» ${ }^{19}$. Las criadas constituían, pues, una población laboral joven, con un oficio que se adecuaba mejor a las solteras, que contribuían así a soportar las cargas familiares, o evitaban ser una preocupación más para sus padres.

Conviene ya sistematizar los datos que hemos apuntado en el análisis de la situación específica de las mujeres. En primer lugar, el acceso al sector laboral se produce para ellas en las peores condiciones, por su falta de cualificación, a lo que debemos añadir su inexperiencia laboral y su nula competitividad. Esta situación venía propiciada por varios factores: no existían apenas otros trabajos para las mujeres y a través de la enseñanza, de la prensa o de la Iglesia se difundían ideas disuasorias que les conducían a que se ocupasen exclusivamente del trabajo doméstico ${ }^{20}$. Se encontraban con muchos impedimentos para trabajar en fábricas y talleres, siendo uno de los principales la oposición de los hombres a admitirlas como compañeras, alegando que, por recibir un salario mucho menor, se constituían en competencia perjudicial; incluso existían prohibiciones legales expresas ${ }^{21}$.

No era precisamente devoción lo que empujaba a tantos miles de mujeres a ser sirvientas, pero fueron frecuentes los textos en los que se relaciona este trabajo con sus capacidades naturales:

«La naturaleza ha dado a nuestro sexo una particular adhesión a los niños. Sean jóvenes o viejas, las mujeres no ven nunca un niño en pañales sin sentir una emoción, que los hombres no pueden comprender; por tanto, no es imposible encontrar una buena niñera» ${ }^{22}$.

Y es que todas las dificultades que encontraban las mujeres en otros campos desaparecían en el servicio doméstico. Esta imagen coincidía plenamente con la mentalidad de quienes aceptaban el trabajo de la mujer como inevitable y, por consiguiente, consideraban que era mejor que trabajase en $\operatorname{casa}^{23}$.

19. Diario de Avisos de Madrid, 27 de enero de 1858.

20. PANADÉs y PoBlet, José: La educación de la mujer según los más ilustres moralistas e higienistas de ambos sexos, Barcelona, Seix, 1877, pp. 22-24.

21. Sobre los problemas de la mujer trabajadora vid. Capel Martínez, $M^{a}$ Rosa: «Mujer y trabajo en la España de Alfonso XIII»..., op.cit., pp. 211-229.

22. PANADÉs y Poblet, José: La educación de la mujer..., op. cit., p. 32.

23. Existen testimonios, algunos literarios, que ilustran labores específicamente femeninas, sobre todo en el campo, como eran la escarda, la vendimia o la recogida de aceituna. Como otros muchos viajeros, Richard Ford lo consideraba una prueba del retraso español y dice: «... tanto las mujeres como los niños trabajan excesivamente en los campos de España, donde el hueso y el músculo humano suplen la falta de la maquinaria más corriente», Manual para viajeros por Castilla y lectores en casa, Madrid, Turner, 1981, p. 13. 


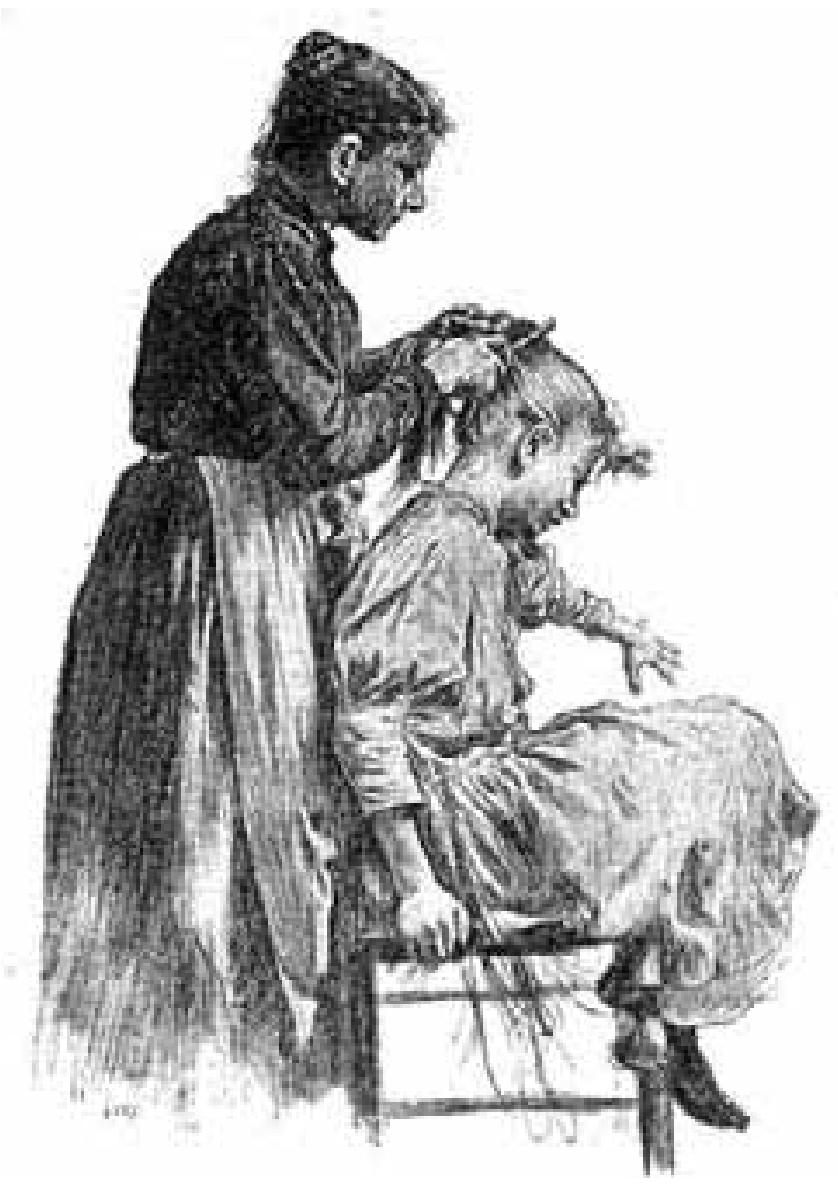

«Escenas de portal» (Nuevo Mundo, n² 21, 30 de abril de 1896)

Dentro de este sector de actividad hubo una especialidad exclusivamente femenina, la de nodrizas o ama de cría, que pasó a componer uno de los tipos populares del siglo XIX. El prototipo de la nodriza era por lo general una emigrante rural que se acercaba a la ciudad para prestar sus servicios a los hijos de las clases acomodadas, amamantando también a pupilos de diversa procedencia: huérfanos, hijos de madres enfermas e incluseros. Para muchas mujeres este era el medio para obtener unos ingresos complementarios que aliviaran su situación económica. Las viudas y madres solteras se ofrecían para trasladarse al domicilio donde prestaban sus servicios, con lo que percibían salarios más altos, porque así quien la contrataba podía controlar su alimentación y comportamiento durante la lactancia y evitar cualquier fraude. Las ofertas eran numerosas y en general se prefería a las jóvenes y a las que habían perdido a su 
propio hijo ${ }^{24}$. La prueba más dura de pasar eran los análisis médicos que según los textos médicos debían garantizar

«... buena dentadura..., con dientes destruidos es defectuosa la masticación y se digiere con dificultad. La nodriza debe hacer uso de una alimentación abundante: feculentos y grasas, es decir, sopas grasosas, patatas, tocino y manteca» ${ }^{25}$.

Esta referencia a las nodrizas nos impide imaginar que fuera una actividad bien considerada por sus contemporáneos y, sin duda, se trataba de una ocupación que se acomodaba perfectamente a la tareas propias que se aconsejaban para la mujer. Cumplía con los requisitos de tratarse de una ocupación temporal, desarrollada en el interior de una casa, y que incorporaba a las necesidades familiares o personales un salario complementario. Además, sus servicios eran una exigencia social en ese momento y su prestación, sobre todo en las ciudades, era la consecuencia de una necesidad económica.

¿De dónde provenía esta situación? Según los testimonios de la época eran muchas las nodrizas que ejercían por dinero ${ }^{26}$, por lo que, incluso, se las acusó de mercenarias y malvadas. Implícitamente, los comentarios sobre las nodrizas iban unidos a la crítica de las madres, pues el hogar era un espacio completamente acotado y encomendado en su funcionamiento exclusivamente a la madre. La función central de la mujer era la maternidad y de ahí la razón por la cual se concedió tanta importancia a que cumpliese con su sagrado deber.

Aunque la española de finales del siglo XIX recibía continuamente mensajes que confirmaban el papel social que le estaba atribuido y que se encaminaba a ayudarle a conseguir nuevas perspectivas de futuro, la realidad era muy distinta. Existía una gran contradicción entre el supuesto progreso que se le prometía y la inmovilidad social que se le reservaba. A ella le correspondían las funciones reproductivas que determinaban y limitaban su destino. Pero quizá lo más interesante de todo aconteció en los años de cambio de centuria, con la toma de conciencia cada vez más generalizada de que la condición jurídica de la mujer derivaba cada vez más hacia posiciones de aproximación al hombre. Pero habría que esperar al siglo XX para que esa igualdad, cada día menos discutida en la teoría, se llene de contenido.

24. El Diario de Avisos de Madrid contiene una amplia colección de anuncios de nodrizas. Así por ejemplo: «En la calle de Roda, n 19, cuarto bajo, taller de carpintero, hay una joven lugareña de 24 años que solicita cría bien para su casa o para la de sus padres; tiene leche de tres meses; en la tienda de comestibles de la misma casa darán razón» (18 de julio de 1868).

25. PAnadés y Poblet, José: La educación de la mujer..., op. cit., p. 32.

26 «Entre las nodrizas hay muchas madres abandonas, que abandonan a su vez a sus hijos para sacar de su afrenta todo el partido posible, vendiendo su sangre a quien mejor la pague», $E l$ Cascabel, enero de 1864. 


\section{BIBLIOGRAFÍA}

Asociación para la enseñanza de la mujer. Bases de la misma y Reglamentos de sus Escuelas, Madrid, Tello, 1959.

Capel, Rosa $M^{a}$ : "Mujer y trabajo en la España de Alfonso XIII», en Mujer y Sociedad en España 1700-1975, Madrid, Cultura, 1982.

Ciclo de Conferencias Dominicales sobre la Educación de la Mujer de la Universidad de Madrid, Madrid, Rivadeneyra, 1869.

Disposiciones adoptadas y publicadas por el Ministerio de la Gobernación desde el 9 de octubre de 1868 hasta la apertura de las Cortes Constituyentes, Madrid, Imprenta de Rojas, 1869.

Francos Rodríguez, José: La mujer y la política españolas, Madrid, Pueyo, 1920.

Memoria del Ateneo de Señoras, Madrid, Rojas, 1869.

NASH, Mary: Familia y Trabajo en España, 1875-1936, Barcelona, Anthropos, 1983.

PANADÉS y POBLET, José: La educación de la mujer según los más ilustres moralistas e higienistas de ambos sexos, Barcelona, Seix, 1877, 2 vols.

PARdo BaZÁN, Emilia: "La mujer española», La España Moderna, 17 (1890), pp. 101-113.

Reglamento de la Escuela de Institutrices: Asociación para la enseñanza de la mujer, Madrid, Noguera, 1882.

Ruiz De Quevedo, Manuel: «La Asociación para la Enseñanza de la mujer» en Boletín de la Institución Libre de Enseñanza, 143 (1883), pp. 17-18.

SÁez de Melgar, Faustina: Manual de la joven adolescente o un libro para mis hijas, Barcelona, Jepus, 1882 (2a ed.).

- Memoria del Ateneo de Señoras, Madrid, Imprenta de Rojas, 1869.

SÁnCHEZ Llama, Iñigo: Galería de escritoras isabelinas. La prensa periódica entre 1833 y 1895, Madrid, Cátedra, 2000.

Simón Palmer, M.C: "La mujer en el siglo XIX: notas bibliográficas», Cuadernos Bibliográficos, 31 y 32 (1974 y 1975), pp 141-198 y 109-150 respectivamente.

Teste, Luis: Viaje por España, Valencia, Castalia, 1959.

VVAA.: Mujer y Sociedad en España(1700-1975), Madrid, Cultura, 1982. 